\title{
Sensitivities of the Tiedtke and Kain-Fritsch Convection Schemes for RegCM4.5 over West Africa
}

\author{
Mojisola Oluwayemisi Adeniyi \\ University of Ibadan, Department of Physics, Ibadan, Oyo State, Nigeria, e-mail: mojisolaadeniyi@yahoo.com
}

\begin{abstract}
Realistic simulation of weather and climate parameters over West Africa is daunting, so the performance of the Tiedtke and Kain-Fritsch convection schemes within version 4.5 of the Regional Climate Model (RegCM4.5) of the International Centre for Theoretical Physics, Trieste is evaluated over West Africa for improved simulation. The two schemes are compared to two traditional mixture schemes (Grell on land and Emanuel on Ocean), outperforming the mixture schemes with reduced magnitude and spatial coverage of dry bias. Both schemes simulate precipitation over West Africa with a low dry bias, however, the Kain-Fritsch convection scheme simulates more realistic precipitation in the West African convective environment. This is associated with the inclusion of a variable cloud radius and the convective available potential energy closure for the Kain-Fritsch in contrast to a fixed cloud radius and moisture convergence of the of the Tiedtke scheme. The simulated outgoing longwave radiation and omega lend support to the spatial variations and amount of simulated precipitation in the different areas by the schemes. The spatial variation of simulated temperature over the target region shows lower bias than precipitation by all the convection schemes. Soil moisture is more accurately simulated (correlation coefficient $\sim 1)$ in the savannah $\left(8-10^{\circ} \mathrm{N}\right)$ and Sahel $\left(22-28^{\circ} \mathrm{N}\right)$ environments by all the convection schemes. Tiedtke performs the most accurate simulations of the pattern and profile of zonal wind which controls climate circulation, with slightly weaker simulations of the Africa easterly jet with core magnitude less than $10 \mathrm{~m} \cdot \mathrm{s}^{-1}$. The accuracy of the KF and Tiedtke in RegCM4.5 in simulating the climate of West Africa is documented for the first time for application in future studies over the region.
\end{abstract}

Keywords: Convective precipitation, West African monsoon, Kain-Fritsch convection scheme, Tiedtke convection scheme, African easterly jet

Submitted 17 January 2018, revised 17 March 2018, accepted 7 February 2019

\section{Introduction}

Rainfall is an important climate parameter and the main source of water for agricultural productivity in West Africa where small-scale farmers dominate the population of farmers. Even when small scale irrigation is used the main source of the irrigation water is rainfall, which increases the water table level during the rainy season such that slight digging near streams and rivers during the dry season yields enough water for small scale irrigation. Accurate prior knowledge of the amount, frequency and intensity of precipitation for a particular rainy season is useful for planning. Understanding of past, present and future climate depends greatly on the use of dynamical General Circulation Models (GCMs), which use a combination of scenarios to represent atmospheric greenhouse gas concentrations and land use for the respective time periods (Adeniyi 2016). The GCMs perform well on continental scales, but their outputs are not realistic on local scales. This calls for the use of either statistical or dynamic Regional Climate Models (RCMs) to transform the output of GCMs on regional scales to a more realistic output closer to observations (Brown et al. 2008; Mendes, Marengo 2010; Jones et al. 2011) based on their higher resolution and fine scale topography (Gao et al. 2016; Adeniyi, Dilau 2018). The ability of such RCMs should be tested for historical simulation, with reanalysis boundary conditions. The performance of the models depends greatly on the physics of the model and the applied physical parameterizations. Atmospheric processes such as turbulent and convective motions can occur on small scale level, this can be smaller than the model grid size, such that these processes cannot be resolved by the model and are usually parameterized. Examples of the processes are convective precipitation, sensible and latent heat fluxes, water vapour fluxes and momentum fluxes.

The West African climate is greatly influenced by deep convection, which has been reported to be the main phenomenon that maintains the African Easterly Jet (AEJ) and the propagation of the African Easterly Wave (AEW) (Leroux, Hall 2009). Furthermore, a considerable proportion of tropical precipitation is convective (Schumacher, Houze 2003). The importance of convective precipitation has led to the development of various convection schemes used in different RCMs. The sensitivity of most of these schemes has been tested and documented. The convective precipitation scheme of the Kuo, Massachusetts 
Institute of Technology-Emanuel is henceforth referred to as Emanuel. The Grell convective precipitation scheme with Arakawa-Schubert (AS) closure is henceforth referred to as Grell 1, while the Grell convective precipitation scheme with Fritsch Chappel closures is referred to as Grell 2. The fourth version of the RCM of the International Centre for Theoretical Physics is henceforth referred to as RegCM4.0. Adeniyi (2014) documented the sensitivity of Emanuel, Grell 1 and Grell 2 schemes in RegCM4.0 for negative and positive El Niño Southern Oscillation phases. It has been documented that Emanuel and Grell2 perform most accurately over ocean and land, respectively (Giorgi et al. 2012; Adeniyi 2014). Gao et al. (2016) compared the performance of both Emanuel and Grell, with one of the models on land and the other on the ocean and the Tiedtke scheme over both the ocean and land in RegCM4.4 over China. Klein et al. (2015) also tested the performance of Betts-Miller-Janjić (BMJ) (Janjić 1994; 2000), Grell-Freitas (GF) (Grell, Freitas 2014) and the Kain-Fritsch (KF) convection trigger (Kain 2004; Ma, Tan 2009) using the WRF model. The KF was found to perform worst compared to Grell Devenyi (GDE) in a simulation of vorticity maxima associated with AEW over West Africa using the WRF model (Noble et al. 2014). Furthermore, Satyaban et al. (2014) tested the sensitivity of the KF, BMJ and GDE schemes using the WRF model over South Africa. Their findings show positive rainfall bias in simulated South African precipitation, with the largest bias in the KF scheme.

Yavinchan et al. (2006) used the KF convection scheme in Numerical Weather Prediction (NWP) models to improve the forecast of convective precipitation over Thailand. The sensitivity of the mass-flux framework of Grell and Dévényi (2002) for convection parameterization with different closures to tracer transport was tested by Arteta et al. (2009), using a coupled model for aerosol tracer transport and a Brazilian regional atmospheric model.

The default schemes in RegCM4 have different trigger mechanism, closure entrainment and detrainment compared to the KF and Tiedtke schemes, thus they are expected to perform differently. Convection in Grell is triggered when a lifted parcel attains moist convection. Convection activation in KF depends on broad scale vertical velocity, while Tiedtke triggers convection near the surface when the parcel temperature is $0.5 \mathrm{~K}$ higher than ambient temperature. Tiedtke employs a moisture convergence-based closure while the closure in KF is based on convective available potential energy (CAPE). The default schemes in RegCM4.5 have some deficiencies when simulating the climate over Africa (Abiodun et al. 2012; Nikulin et al. 2012), particularly relating to the diurnal precipita- tion variation. Another deficiency in the default scheme as documented by Im et al. (2014), is the inability of default scheme to capture the intensity of an isolated maximum precipitation over the southwestern coast of Guinea. The newer schemes are expected to have potentials for improving the performance of RegCM4.5 based on their strong documented performance in other models and areas. For example, the Kain-Fritsch scheme has been reported to simulate a more realistic diurnal precipitation cycle over Africa and Thailand (Yavinchan et al. 2006; Nikulin et al. 2012). Furthermore, moisture convergence-based closure applied to the Tiedtke scheme has been used to improve the simulation of Madden Julian Oscillation (Liu et al. 2005 ) with respect to the deep convective scheme of Zhang and McFarlane with the CAPE based closure. The sensitivity of the Tiedtke and KF convective precipitation schemes in RegCM4.5 over West Africa is yet to be documented. This is necessary to guide future simulations over the area on the best parameterization for convective precipitation. This study simulates the climate of West Africa using both the Tiedtke and KF convection schemes in RegCM4.5 and evaluates the performance of the convection schemes over this region. The model description, experimental set up and evaluation datasets are presented in Section 2. The results are then analysed and discussed in Section 4, while Section 5 presents the conclusions.

\section{Model description, simulation datasets and experi- mental set up}

The RegCM4.5 is used to simulate the West African climate by combining the Emanuel and Grell 2 convection schemes with Emanuel used on the ocean and Grell2 on the land). This is performed along with the Tiedtke and KF convection schemes, which are applied over both land and ocean. This is carried out to determine the most accurate schemes over the target area in order to improve future precipitation simulations and downscaling. Six experiments are carried out with the same model parameters varying only the convection schemes and initialization dates.

Simulations are run over West Africa (Fig. 1) with the longitude and latitude centred on $0.0^{\circ} \mathrm{E}$ and $12.5^{\circ} \mathrm{N}$, respectively. The RegCM4.5 model has two cores: hydrostatic and non-hydrostatic. The hydrostatic core is used with 23 pressure levels for the experiments. Pressure levels $1-23$ correspond to $25,75,125,175,225,275,325,375$, $425,475,525,575,625,675,725,775,825,870,910,945$, 970, 995 and $1005 \mathrm{hPa}$, respectively. Giorgi et al. (2012) documented an accurate performance of the Normal Mercator cartographic projection in the tropics, thus it is used 


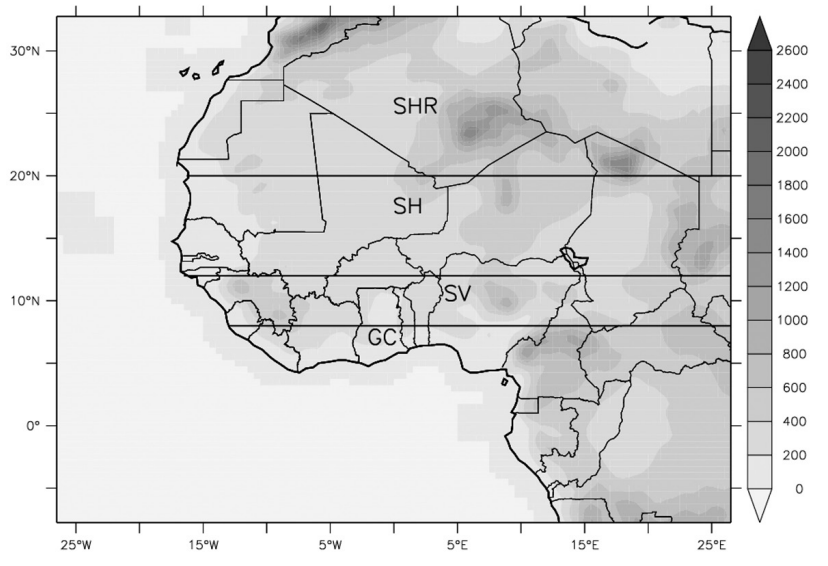

Fig. 1. Map of the simulation domain depicting the key regions over West Africa which are the Guinea Coast represented by GC, the savannah as SV, the Sahel as SH and the Sahara Desert as SHR; the spatial variation of the topography of the simulation domain is filled using inverse grey scale in meters above sea level

to project the simulation datasets to the West African domain on a $50 \mathrm{~km} \times 50 \mathrm{~km}$ spatial grid. The Global 30 Arc-Second Elevation topography data set is used for these simulations, with a time step of $150 \mathrm{~s}$. Era-Interim 1.5 Reanalysis data sets (Dee et al. 2011) are used as initial and lateral/surface boundary conditions in the six simulations. The Optimum Interpolated (OI) Sea Surface Temperature (SST) weekly SST data, updated every $6 \mathrm{~h}$ is used as the oceanic boundary condition for the three simulations. Three of the experiments start from 00 GMT 01 March, 2008 while the remaining three are initialized at 00 GMT 01 January, 2008. All experiments end on 00 GMT 01 November, 2008. The analysis starts from June to allow up to a 3-5 months spin up for the avoidance of possible errors from persisting initial soil moisture properties. Each convective parameterization has two simulations with the two different initialization times. The ensemble mean of the simulations with the different initializations is used for each convective parameterization. The Adeniyi (2017) model configurations with the traditional mixture of Grell (over land) and Emanuel (over ocean) convective parameterizations are used for the simulations, with the exception of the additional simulations with the KF and Tiedtke convective parameterizations. The Tiedtke and KF are used over the whole domain for both land and ocean in order to document their respective performances. The Community Land Model version 4.5 (CLM 4.5) is available in RegCM4.5, and the Land Surface Model (LSM) has been reported for its good performance over West Africa (Diallo 2015) when used with the Emanuel convective precipitation scheme. The response of the Emanuel scheme to surface heating is usually strong, increasing when convection is triggered. The Biosphere Atmosphere Transfer Scheme (BATS) includes only two soil levels and uses the force-restore method making its response to solar heating very strong with the release of sensible heat to the convective precipitation scheme. It thus underestimates surface albedo and overestimates net radiation (Im et al. 2014). This effect amplifies the convection in Emanuel when used together in a simulation. This corroborates the positive bias in Sahelian precipitation reported by Steiner et al. (2009) with the use of BATS and the Emanuel scheme. On the other hand, CLM includes several layers of soil. This increases the inertia of the soil surface temperature, reduces the response to solar heating and consequently the release of sensible heat to the convective precipitation scheme. As a result, convection forcing is reduced by CLM. Based on this argument and the simulation output, Gao et al. (2016) reported a more realistic climate simulation from the combination of CLM with Emanuel but an unrealistically dry bias when CLM is combined with Grell. Therefore, BATS LSM is used in the three experiments, since both Grell and CLM usually simulate dry bias, and thus a combination of both schemes will lead to an unrealistically dry bias in precipitation simulations. Emanuel usually simulates wet bias over land (Sylla et al. 2011), yet simulations over ocean tend to be more realistic (Giorgi et al. 2012). The radiation scheme used in RegCM4.5 is similar to the scheme used in the National Center for Atmospheric Research (NCAR), Community Climate System Model version 3 (CCM3). More information on the RegCM4.5 model dynamics and physics are described in Giorgi et al. (2012); Elguindi et al. (2014) and Giorgi et al. (2016).

\section{Data and methods \\ 3.1. Validation datasets}

Precipitation simulation is evaluated by comparing the simulations with two different observational datasets: 1) the monthly rainguage based gridded Climate Research Unit (CRU), time series (TS), version 3.22 data on a $0.5 \times 0.5$ degree grid (Mitchell, Jones 2005) and 2) the Global Precipitation Climatology Project (GPCP) daily precipitation version 1DD V1.1 (mm/day) on a 1 degree grid (Huffman et al. 2001; Yin et al. 2004; Bolvin et al. 2009).

Temperature simulations are compared to two different observational datasets the CRU TS version 3.22 and UDELv4.01. Outgoing longwave radiation (OLR) simulations are compared to the interpolated National Oceanic and Atmospheric Administration (NOAA) OLR satellite retrieved data (Liebmann, Smith 1996). The OLR data is a 1 degree by 1 degree daily mean OLR flux at the top of the atmosphere. It is being derived using multispectral regression models (Ellingson et al. 1989) from high resolution infrared radiation sounder radiance observations on board NOAA television infrared observation 
satellite (TIROS-N) series and meteorological operational satellite (MetOp) (Ellingson et al. 1989). Soil moisture simulations are validated using Era-Interim reanalysis data. Omega, zonal and meridional wind from Era-Interim reanalysis are also used as surrogate observed data to validate the simulated zonal (u) wind, meridional (v) wind, omega vertical velocity and relative vorticity. The reanalysis data are on 30 vertical levels from the surface to $50 \mathrm{hPa}$.

\subsection{The Kain-Fritsch and Tiedtke schemes}

The KF and Tiedtke schemes share common working principles. They are mass flux parameterizations (Tiedtke 1989; Kain, Fritsch 1993), based on the Lagrangian parcel method (Simpson, Wiggert 1969; Kreitzberg, Perkey 1976), and vertical momentum dynamics (Donner 1993) for the determination of instability and the properties of resulting convective clouds. Both schemes distinguish penetrative and shallow convection. However, they differ in their trigger mechanism, closure entrainment and detrainment (Kain, Fritsch 1990). The Tiedtke scheme compares the temperature of the parcel very close to the surface at ambient temperature, and triggers convection if the parcel is $0.5 \mathrm{~K}$ warmer than its environment. Convection triggering in the KF scheme is controlled by large scale velocity in the vertical direction. Mid-level convection above the planetary boundary layer (PBL) is also considered
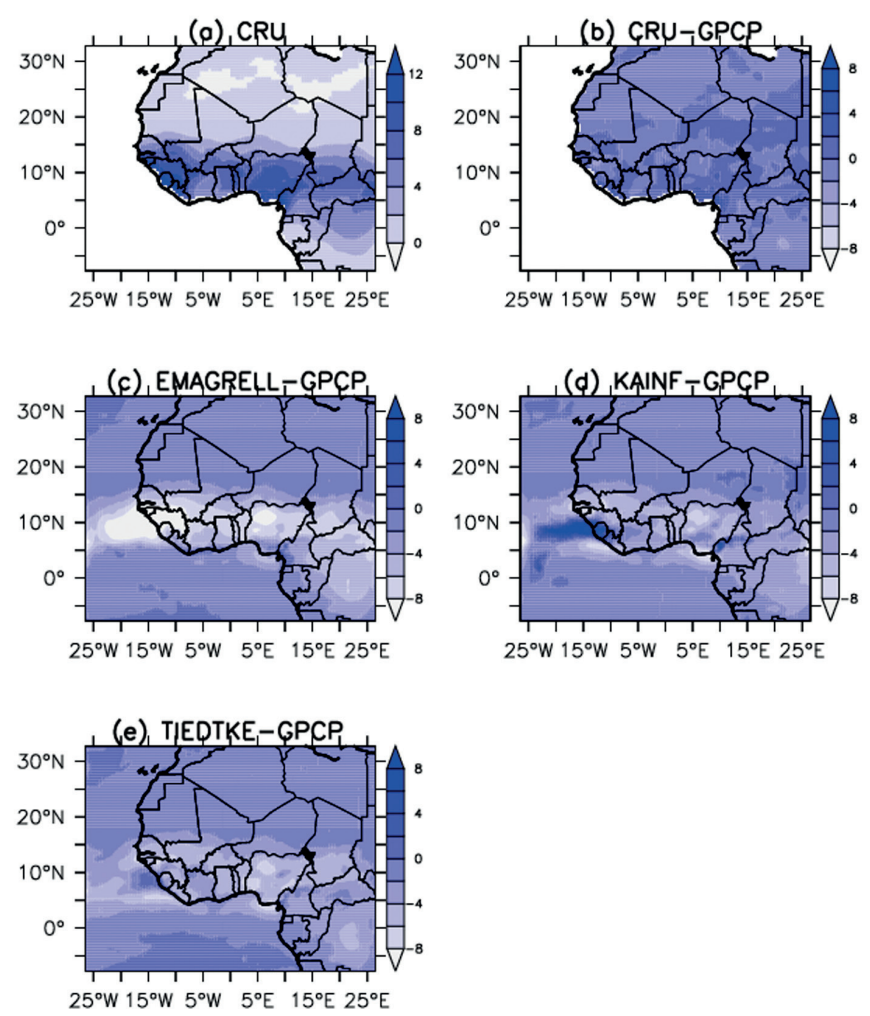

Fig. 2. Mean seasonal June-July-August-September precipitation [mm day ${ }^{-1}$ ] in 2008 for the (a) GPCP observations, (b) CRU observations minus GPCP observations, (c) Emanuel-Grell scheme simulations minus GPCP observations, (d) Kain-Fritsch scheme simulations minus GPCP observations and (e) Tiedtke scheme simulations minus GPCP observations in the Tiedtke scheme. However, only convection is considered above the PBL in the KF scheme.

The closure assumption in the Tiedtke scheme is based on moisture convergence, while for the KF scheme, it is based on the CAPE for an entraining parcel (Kain, Fritsch 1990; Bechtold et al. 2001). In addition, Tiedtke depends on turbulent mixing and organized inflow, while the KF scheme depends only on turbulent mixing.

The closure in KF is based on undiluted ascent, such that more CAPE is available for elimination.

It provides relatively realistic rainfall rates for a broad range of convective environments leading to a relatively better prediction of convective intensity (Kain et al. 2003) than other convective precipitation schemes. Another difference between the two schemes is that the cloud radius is variable in KF while it is fixed in Tiedtke. As a result, convective precipitation is more realistic in KF entraining/detraining plume model, as described in detail in Kain and Fritsch (1990).

\section{Results and discussion \\ 4.1. Precipitation}

Seasonal (JJAS) observed and simulated precipitation $\left[\mathrm{mm} \cdot \mathrm{day}^{-1}\right]$ are shown in Figure 2. The two observational datasets for precipitation can only be compared over land (Fig. 2b), as CRU (Fig. 2a) has no record over the ocean. 
The general high values for coastal areas that decrease with distance towards the north are depicted in the two datasets. Furthermore, the two observational datasets agree on the precipitation maxima for the southwestern area of the simulation domain (Guinea highlands, Sierra Leone Mountains, Jos plateau in Nigeria, Cameroon Mountain and the coast of Nigeria). The region with the maximum west-east belt of precipitation is depicted as the inter-tropical convergence zone which undulates between 7 and $12^{\circ} \mathrm{N}$ latitudes in the observational data (Fig. 2a). Emanuel-Grell simulates the mean daily precipitation rate for the GPCP observation with a dry bias on land at the southern part of the simulation domain (above $5^{\circ} \mathrm{N}$ ), where a substantial mean precipitation rate is observed. This corroborates the reported performance of Grell (Sylla et al. 2011; Adeniyi 2014). Note that the bias is lower below $5^{\circ} \mathrm{N}$. The KF scheme (Fig. 2d) captures high observed precipitation for the Coastal Guinea, Sierra Leone, Liberia, and over the ocean, but with wet a bias between 5 and $10^{\circ} \mathrm{N}$. It simulates little dry bias over the land and ocean in the remaining areas of the simulation domain. However, the structural pattern of precipitation is comparable with the observations; low (high) precipitation rate is simulated where low (high) precipitation rate is observed. The precipitation rate is better simulated below $10^{\circ} \mathrm{N}$ within the region of substantial precipitation observations $\left(0^{\circ} \mathrm{N}-15^{\circ} \mathrm{N}\right.$, Fig. $\left.2 \mathrm{a}\right)$. Tiedtke (Fig. 2e) simulates little dry bias over the whole area of the simulation domain. However, it replicates the structural pattern of the observed precipitation distribution from the north to the south. Bias is lower for regions below $8^{\circ} \mathrm{N}$ and above $17^{\circ} \mathrm{N}$ on land using Tiedtke. Kothe et al. (2014) also reported dry bias in simulated total precipitation based on the Tiedtke scheme used in WRF over West Africa, specifically between $-10^{\circ} \mathrm{N}$ and $10^{\circ} \mathrm{N}$. The KF scheme simulates precipitation relatively accurately with lower dry bias than Tiedtke particularly for the south-eastern part of the simulation domain (Fig. 2). This is in line with the work of Arteta et al. (2009) and Klein et al. (2015), where KF exceeds the performance of other convection schemes used in their investigation. Yavinchan et al. (2006) used KF to improve the simulation of convective precipitation over Thailand. Dierer and Schubiger (unpublished) also reveal a better performance of the KF scheme compared to Tiedtke. The KF and Tiedtke simulate precipitation with a lower bias compared to Emanuel-Grell, and in particular, KF is relatively more accurate than the other schemes in term of lower bias.

\subsection{Temperature}

The Figure 3 compares the observed and simulated mean JJAS near surface air temperature over West Africa. The CRU and UDEL observational data show a similar pattern of temperature distribution over the simulation domain,
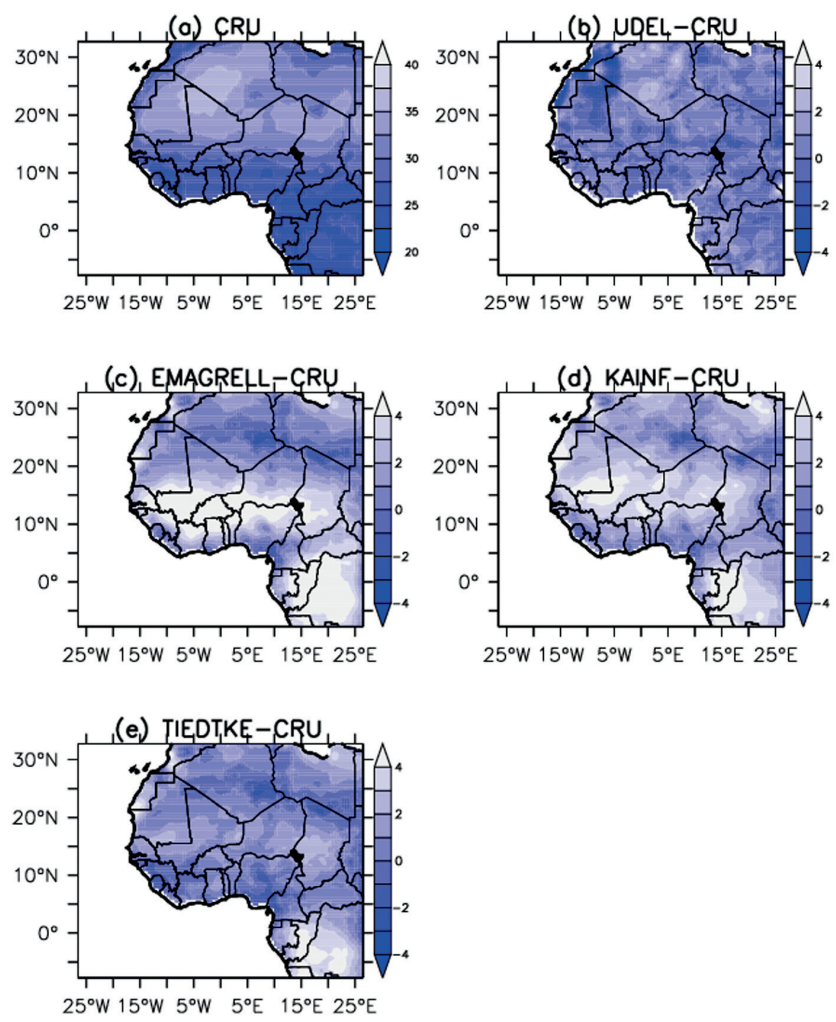

Fig. 3. Mean JJAS near surface air temperature $\left[{ }^{\circ} \mathrm{C}\right]$ in 2008 for the (a) CRU observations, (b) observed UDEL minus CRU observations, (c) Emanuel-Grell scheme simulations minus CRU observations, (d) Kain-Fritsch scheme simulations minus CRU observations and (e) Tiedtke scheme simulations minus CRU observations 
with the exception of the extended areas of high temperature in UDEL over the northwestern part of the domain, more specifically, over southwestern (SW) Algeria (Figs. 3a and b). For all cases, a warm bias is simulated at the southern part of the simulation domain with Emanuel-Grell attaining the highest bias. All simulations capture the observed region of high temperature, the Sahara Thermal Low (STL) in SW Algeria, at approximately $25^{\circ} \mathrm{N}$, with varying spatial coverage and magnitude (Fig. 3c-e). All simulations also capture the general spatial pattern of temperature, with higher temperatures at the north that decrease towards the south. The cold temperature observed at the north western tip of the land area (Morocco) is seen in all cases. In addition, a warm bias between latitudes 10 and $15^{\circ} \mathrm{N}$, and also below $0^{\circ} \mathrm{N}$ (Figs. 3c-e), can be observed in the simulations. In general, temperature is better captured by all the convection schemes compared to precipitation. This is the norm based on the complex processes of convective precipitation.

\subsection{Outgoing Longwave Radiation (OLR)}

The NOAA and simulated OLR are shown in Figure 4. The simulations are compared with the interpolated NOAA satellite retrieved OLR. The observed OLR pattern is such that OLR below $240 \mathrm{~W} \cdot \mathrm{m}^{-2}$ lies below $12.5^{\circ} \mathrm{N}$ on land, while those values greater than $240 \mathrm{~W} \cdot \mathrm{m}^{-2}$ are located above $12.5^{\circ} \mathrm{N}$ (Fig. 4a). Areas with a low OLR indicate high cloud coverage and convective activity, which should eventually lead to high precipitation. On the ocean, the region of OLR $<240 \mathrm{~W} \cdot \mathrm{m}^{-2}$ is shifted southwards (Fig 4a). The north generally has higher OLR values, which is as expected, since little or no precipitation is observed or simulated in the north (Figs. 2 and 4). Emanuel-Grell shows higher OLR values at areas with $<240 \mathrm{~W} \cdot \mathrm{m}^{-2}$ in the observations (Fig. 4b). This is revealed by positive a bias in simulated OLR between 5 and $15^{\circ} \mathrm{N}$, indicating a lower convective activity, which corroborates the dry bias in simulated precipitation by the mixed convection scheme (Figs. 2c and 4b). The KF scheme outputs OLR $<240 \mathrm{~W} \cdot \mathrm{m}^{-2}$ almost at the same locations as the NOAA OLR retrievals. This is the reason for low bias in simulated OLR between 5 and $10^{\circ} \mathrm{N}$ (Fig. 4c). It is in line with the low bias in simulated precipitation by KF (Fig. 2d). Tiedtke slightly overestimates convective activity (medium negative OLR bias) over the SW and part of the south-eastern area of the simulation domain. The increase in convective activity in these areas is not seen in the precipitation bias (Fig. 2e). The region of slight positive bias that should be consistent with the negative OLR bias is shifted to the ocean for precipitation (Figs. 2e, 4c).

\subsection{Soil moisture}

The correlation coefficient between simulated mean daily accumulated soil moisture at level 2 and EraInterim soil moisture at level 2 is displayed in Figure 5. Soil moisture is well captured over the larger part of the simulation domain. However, Emanuel-Grell fails to capture the soil moisture pattern at the Sahel. Although it simulates soil moisture well for the northern areas beyond $22^{\circ} \mathrm{N}$ and at the savannah $\left(8-10^{\circ} \mathrm{N}\right)$. The KF scheme captures soil moisture best at the Sahel, with a correlation value of $\sim 1.0$ for some areas. The Tiedtke scheme performs second to the KF scheme over the Sahel. The performance of Tiedtke in soil moisture simulation is best in Central Africa, followed by KF. The simulated pattern for the savannah area $\left(8-10^{\circ} \mathrm{N}\right)$ and the Sahel $\left(22-28^{\circ} \mathrm{N}\right)$ is comparable with observations in all the simulations. All model simulations show a reduced wetness (not shown) north from $15-33^{\circ} \mathrm{N}$ relative to the south.

\subsection{African Easterly Jet and Tropical Easterly Jet}

The AEJ and the Tropical Easterly Jet (TEJ) in EraInterim and their simulations are shown from the vertical profile of zonal wind in Figure 6. All simulations show a negative jet around $200 \mathrm{hPa}$ and $600 \mathrm{hPa}$, which can conveniently represent the TEJ and AEJ, respectively. The TEJ is observed within the documented pressure level and latitudinal locations of $100-200 \mathrm{hPa}$ and $5^{\circ}$ to $15^{\circ} \mathrm{N}$, respectively (Chen, Loon 1987). However, the surrogate observed data (Era-Interim) shows the TEJ centred at $200 \mathrm{hPa}$ and within -2 to $25^{\circ} \mathrm{N}$. This jet has a major influence on weather system development over West Africa and should be simulated correctly for applicability in predictions (Chen, Loon 1987). The vertical and latitudinal patterns of surrogate observed zonal wind is better captured by Tiedtke. Tiedtke simulates TEJ with a centre of $<-10 \mathrm{~m} \cdot \mathrm{s}^{-1}$ at a pressure level close to that of Era-Interim. The remaining two runs observe the centres above $200 \mathrm{hPa}$, and with a weaker magnitude than Tiedtke. The influence of AEJ on weather systems over West Africa is reported to be the strongest of all the phenomena that affect the pattern of rainfall in the monsoon region (Cook 1999; Diedhiou et al. 1999). It is important that the AEJ be well simulated by RCMs, as it is required for climate studies, predictions and downscaling. The AEJ in Tiedtke is not strong $(>-10)$ though at a latitudinal location $\left(11^{\circ} \mathrm{N}\right)$ relatively close to that of Era-Interim $\left(14^{\circ} \mathrm{N}\right)$. Emanuel-Grell has the most intensified jet core with the highest low-level baroclinicity $\left(<-10 \mathrm{~m} \cdot \mathrm{s}^{-1}\right)$ centred at $600 \mathrm{hPa}$, yet the latitudinal location is centred on $7.5^{\circ} \mathrm{N}$. The AEJ in KF is centred 

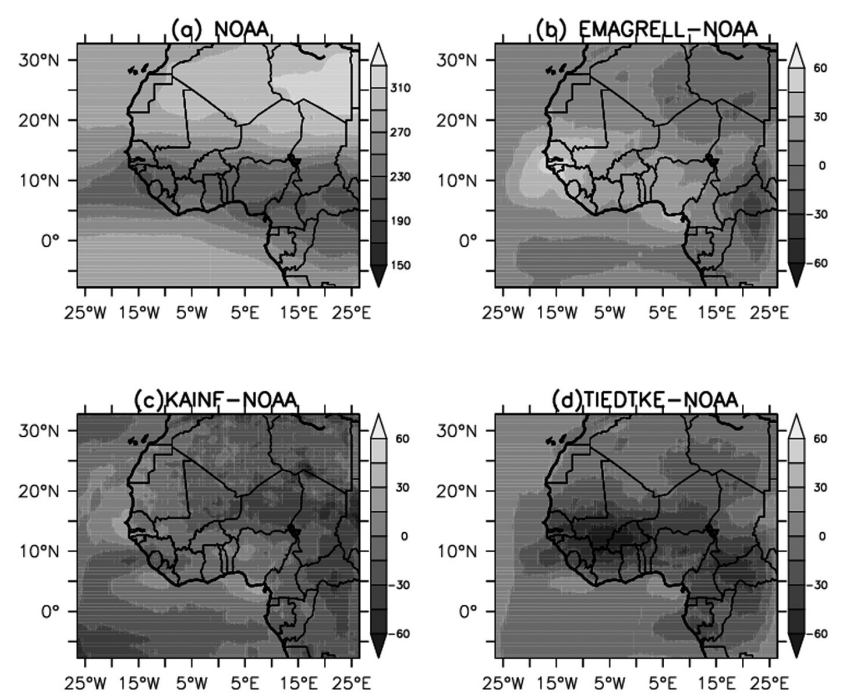

Fig. 4. Mean JJAS outgoing longwave radiation $\left[\mathrm{W} \cdot \mathrm{m}^{-2}\right]$ in 2008 for the (a) NOAA retrievals, (b) Emanuel-Grell scheme simulations minus NOAA retrievals, (c) Kain-Fritsch scheme simulations minus NOAA retrievals and (d) Tiedtke scheme simulations minus NOAA retrievals
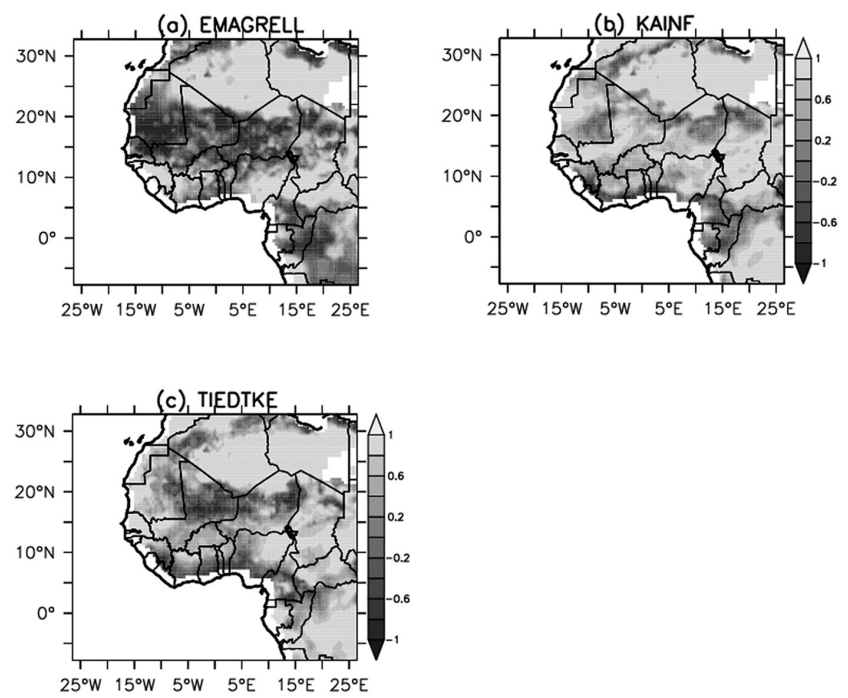

Fig. 5. Correlation coefficient between the Era-Interim reanalysis mean JJAS soil moisture and simulations in 2008 for the (a) EmanuelGrell scheme, (b) Kain-Fritsch scheme and (c) Tiedtke scheme

at $9^{\circ} \mathrm{N}$. All the simulations depict the presence of the AEJ and TEJ, but with weaker wind magnitudes and or at different latitudinal location. The Tiedtke simulation pattern of cross-sectional zonal wind is closest to the observations, but with a weaker AEJ.

\subsection{Omega vertical velocity}

Omega vertical velocity simulation is compared to surrogate observed omega in Figure 7. The Era-Interim reanalysis shows a pattern of latitudinal variations in omega (Fig. 7a). This is fairly depicted in the three model runs, however, the vertical extent of the ascent (negative omega) or descent (positive omega) differs from the surrogate observed omega. The scheme with the closest simulations to the observations is Tiedtke, followed by KF, with the least closest being Emanuel-Grell. The ascent in KF does not have enough latitudinal extension compared to Era-Interim. The simulated vertical extent of ascent in Emanuel-Grell is comparable with the Era-Interim, but with a low magnitude in the latitudinal extent. The ascent mostly leads to convection in the presence of sufficient humidity and consequent precipitation. This reveals the reason for the reduced amount of precipitation simulated by Emanuel-Grell with respect to other convective precipitation schemes (Fig. 2c).

\section{Conclusion}

In an attempt to lessen the difficulty involved in the realistic simulation of West African climate, the simulation performance of the KF and Tiedtke convection schemes in RegCM4.5 during the monsoon period over West Africa 

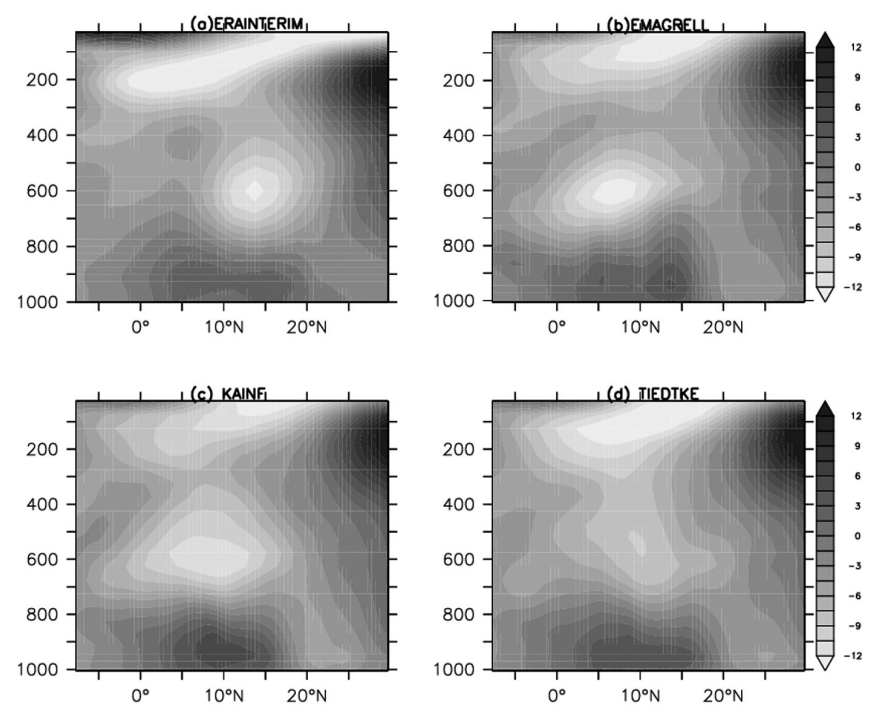

Fig. 6. The vertical profile of the zonal mean JJAS u wind $\left[\mathrm{m} \cdot \mathrm{s}^{-1}\right]$ in 2008 for the (a) Era-Interim reanalysis, (b) Emanuel-Grell scheme simulations, (c) Kain-Fritsch scheme simulations, and (d) Tiedtke scheme simulations; the zonal mean is taken between $15^{\circ} \mathrm{W}$ and $15^{\circ} \mathrm{E}$
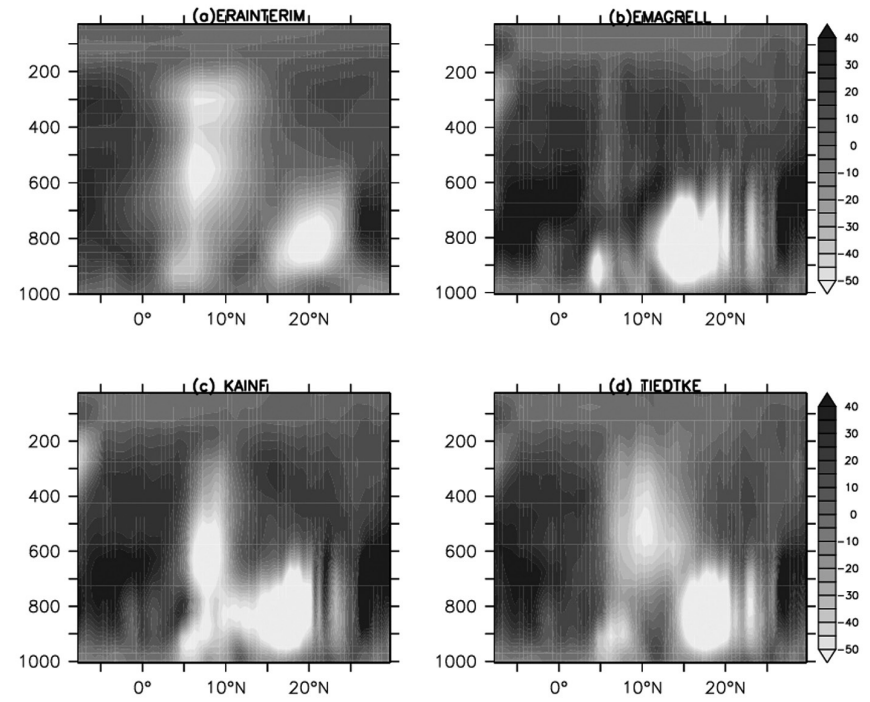

Fig. 7. The vertical profile of the zonal mean JJAS omega vertical velocity $\left[\cdot 10^{-3} \mathrm{~Pa} \cdot \mathrm{s}^{-1}\right]$ in 2008 for the (a) Era-Interim reanalysis, (b) Emanuel-Grell scheme simulations, (c) Kain-Fritsch scheme simulations, and (d) Tiedtke scheme simulations; the zonal mean is taken from $15^{\circ} \mathrm{W}$ to $15^{\circ} \mathrm{E}$

is tested. The simulation performance of the existing Emanuel and Grell convection schemes are also compared using Emanuel over the ocean and Grell over the land. This was carried out in order to determine the most accurate convective precipitation scheme for improved climate simulation over West Africa. The results reveal similarities in the sensitivities of both schemes, yet a wetter bias in KF exists over the ocean and the coast of Sierra-Leone and Liberia. Both schemes simulate precipitation over the simulation region with a low bias. The KF however, simulates more realistic precipitation compared to Tiedtke. The Emanuel-Grell simulated precipitation shows a dry bias for the southern area of the simulation domain. Spatial coverage of simulated precipitation in Tiedtke and KF are closer to the observations. Temperature is better simulated than precipitation, as expected, due to the complexity of cloud formation and convective precipitation processes. The general pattern of spatial variation of temperature exhibits high temperature at the north, decreasing towards the south over West Africa. This is well captured by all the schemes. A cold region at the north western part of the simulation domain (Morocco) is also captured by all the schemes. Furthermore, the highest temperatures, located in the northwest central $\left(-7\right.$ to $3^{\circ} \mathrm{E} ; 18$ to $\left.27^{\circ} \mathrm{N}\right)$ region of STL are well simulated. The simulated outgoing longwave radiation and soil moisture have a spatial coverage and magnitude that supports the precipitation simulation i.e. a low OLR in regions of high of precipitation and vice versa. High correlation coefficients exist between the simulated soil moisture and the reanalysis in most areas of the simulation domain. The AEJ and TEJ are fairly captured by all schemes. Tiedtke simulates the most accurate zonal 
wind spatial pattern and profile, but with a weaker AEJ. Omega, which is directly related to descent/ascent and suppression/convection, is fairly captured by the schemes. All schemes demonstrate the latitudinal variations in omega, but with varying latitudinal, vertical extent and strength with respect to the Era- Interim datasets. Tiedtke simulates the closest spatial and vertical profile to the Era-Interim omega, followed by KF. The least accurate omega variation is produced by Emanuel-Grell. The simulations improve generally with the use of KF and Tiedtke. Prior to this study, the performance of KF and Tiedtke in RegCM4.5 in climate simulation over West Africa has not been documented. The results show the location where each schemes are more accurate than the others based on the biases, correlation coefficient and pattern. Future simulations can use the accurate schemes documented in this study for specific areas or regions in other studies. The simulation domain of this study covers only West Africa, so the results can only be applied within West Africa and not beyond. For application in other areas or regions, a similar study should be conducted over such a region. In future simulations, higher horizontal and vertical resolutions could be used for more realistic simulations.

\section{Acknowledgements}

The RegCM4.5 used in this study was made available by the Earth System Physics Group of ICTP. Datasets from the Climate Research Unit of the University of East Anglia, the Global Precipitation Climatology Project, the University of Delaware, Era-Interim, the National Oceanic and the Atmospheric Administration are used for model evaluation.

Bibliography

Abiodun B.J., Adeyewa Z.D., Oguntunde P.G, Salami A.T. Ajayi V.O., 2012, Modeling the impacts of reforestation on future climate in West Africa, Theoretical and Applied Climatology, 110 (1-2),77-96, DOI: 10.1007/s00704-012-0614-1

Adeniyi M.O., 2014, Sensitivity of different convection schemes in RegCM4.0 for simulation of precipitation during the Septembers of 1989 and 1998 over West Africa, Theoretical and Applied Climatology, 115 (1-2), 305-322, DOI: 10.1007/ s00704-013-0881-5

Adeniyi M.O., 2016, The consequences of the IPCC AR5 RCPs 4.5 and 8.5 climate change scenarios on precipitation in West Africa, Climatic Change, 139 (2), 245-263, DOI: 10.1007/ s10584-016-1774-2

Adeniyi M.O., 2017, Modeling the impact of changes in Atlantic sea surface temperature on the climate of West Africa,
Meteorology and Atmospheric Physics, 129 (2), 187-210, DOI: $10.1007 / \mathrm{s} 00703-016-0473-\mathrm{x}$

Adeniyi M.O., Dilau K.A., 2018, Assessing the link between Atlantic Niño 1 and drought over West Africa using CORDEX regional climate models, Theoretical and Applied Climatology, 131 (3), 937-949, DOI: 10.1007/s00704-016-2018-0

Arteta J., Marécal V., Rivière E.D., 2009, Regional modelling of tracer transport by tropical convection - Part 1: Sensitivity to convection parameterization, Atmospheric Chemistry and Physics, 9 (18), 7081-7100, DOI: 10.5194/acp-9-7081-2009 Bechtold P., Bazile E., Guichard F., Mascart P., Richard E., 2001, A mass-flux convection scheme for regional and global models, Quarterly Journal of the Royal Meteorological Society, 127 (573), 869-886, DOI: 10.1002/qj.49712757309

Bolvin D.T., Adler R.F., Huffman G.J., Nelkin E.J., Poutiainen J.P., 2009, Comparison of GPCP monthly and daily precipitation estimates with high-latitude gauge observations, Journal of Applied Meteorology and Climatology, 48 (9), 1843-1857, DOI: 10.1175/2009JAMC2147.1

Brown C., Greene A., Block P., Giannini A., 2008, Review of downscaling methodologies for Africa climate applications, IRI Technical Report 08-05, International Research Institute for Climate and Society, Columbia University, DOI: 10.7916/ D8M04C88

Caminade C., Terray L., 2010, Twentieth century Sahel rainfall variability as simulated by the ARPEGE AGCM, and future changes, Climate Dynamics, 35 (1), 75-94, DOI: 10.1007/ s00382-009-0545-4

Chen T.-C., van Loon H., 1987, Interannual variation of the tropical easterly jet, Monthly Weather Review, 115 (8), 1739-1759, DOI: 10.1175/1520-0493(1987)115<1739:IVOTTE >2.0.CO;2

Cook K.H., 1999, Generation of the African easterly jet and its role in determining West African precipitation, Journal of Climate, 12 (5), 1165-1184, DOI: 10.1175/1520-0442(1999)012<1165:GOTAEJ $>2.0$. CO;2

Dee D.P., Uppala S.M., Simmons A.J., Berrisford P., Poli P., Kobayashi S., Andrae U., Balmaseda M.A., Balsamo G., Bauer P., Bechtold P., Beljaars A.C.M., van de Berg L., Bidlot J., Bormann N., Delsol C., Dragani R., Fuentes M., Geer A.J., Haimberger L., Healy S.B., Hersbach H., Hólm E.V., Isaksen L., Kållberg P., Köhler M., Matricardi M., McNally A.P., Monge-Sanz B.M., Morcrette J.-J., Park B.-K., Peubey C., de Rosnay P., Tavolato C., Thépaut J.-N., Vitart F., 2011, The ERA-Interim reanalysis: configuration and performance of the data assimilation system, Quarterly Journal of the Royal Meteorological Society, 137 (656), 553-597, DOI: 10.1002 qj. 828

Diallo I., 2015, Sensitivity of West African Monsoon water cycle to land surface schemes in RegCM4, AGU Fall Meeting, San Francisco, 16 December 2015, Abstract id. A33J-0322 
Diedhiou A., Janicot S., Viltard A., de Felice P., Laurent H., 1999, Easterly wave regimes and associated convection over West Africa and tropical Atlantic: results from NCEP/NCAR and ECMWF reanalyses, Climate Dynamics, 15 (11), 795-822, DOI: $10.1007 / \mathrm{s} 003820050316$

Donner L.J., 1993, A Cumulus parameterization including mass fluxes, vertical momentum dynamics, and mesoscale effects, Journal of Atmospheric Sciences, 50 (6), 889-906, DOI: 10.1175/1520-0469(1993)050<0889:ACPIMF>2.0.CO;2

Elguindi N., Bi X., Giorgi F., Nagarajan B., Pal J., Solmon F., Rauscher S., Zakey A., O'Brien T., Nogherotto R., Giuliani G., 2014, Regional Climate Model RegCM Reference Manual, version 4.5, Trieste, Italy, available at https://gforge.ictp.it/ gf/download/docmanfileversion/95/1585/ReferenceMan.pdf (data access 13.02.2019)

Ellingson R.G., Yanuk D.J., Lee H.-T., Gruber A., 1989, A technique for estimating outgoing longwave radiation from HIRS radiance observations, Journal of Atmospheric and Oceanic Technology, 6, 706-711, DOI: 10.1175/1520-0426(1989)006<0706:ATFEOL >2.0.CO;2

Gao X., Shi Y., Giorgi F., 2016, Comparison of convective parameterizations in RegCM4 experiments over China with CLM as the land surface model, Atmospheric and Oceanic Science Letters, 9 (4), 246-254, DOI: 10.1080/16742834.2016.1172938

Giorgi F., Coppola E., Solmon F., Mariotti L., Sylla M.B., Bi X., Elguindi N., Diro G.T., Nair V., Giuliani G., Turuncoglu U.U., Cozzini S., Güttler I., O’Brien T.A., Tawfik A.B., Shalaby A., Zakey A.S., Steiner A.L., Stordal F., Sloan L.C., Brankovic C., 2012, RegCM4: model description and preliminary tests over multiple CORDEX domains, Climate Research, 52, 7-29, DOI: $10.3354 /$ cr01018

Giorgi F., Solmon F., Giuliani G., 2016, Regional Climatic Model RegCM User's Guide, version 4.5, Trieste, Italy, available at https://gforge.ictp.it/gf/download/docmanfileversion/94/1584/ UserGuide.pdf (data access 13.02.2019)

Grell G.A., Dévényi D., 2002, A generalized approach to parameterizing convection combining ensemble and data assimilation techniques, Geophysical Research Letters, 29 (14), DOI: 10.1029/2002GL015311

Grell G.A., Freitas S.R., 2014, A scale and aerosol aware stochastic convective parameterization for weather and air quality modelling, Atmospheric Chemistry and Physics, 14 (10), 5233-5250, DOI: $10.5194 /$ acp-14-5233-2014

Huffman G.J., Adler R.F., Morrissey M., Bolvin D., Curtis S., Joyce R., McGavock B., Susskind J., 2001, Global precipitation at one-degree daily resolution from multi-satellite observations, Journal of Hydrometeorology, 2 (1), 36-50, DOI: 10.1175/1525-7541(2001)002<0036:GPAODD>2.0.CO;2

Im E.-S., Gianotti R.L., Eltahir E.A.B., 2014, Improving the simulation of the West African Monsoon using the MIT regional climate model, Journal of Climate, 27, 2209-2229, DOI: 10.1175/JCLI-D-13-00188.1

Janjić Z.I., 1994, The step-mountain eta coordinate model: further developments of the convection, viscous sublayer, and turbulence closure schemes, Monthly Weather Review, 122 (5), 927-945, DOI: 10.1175/1520-0493(1994)122<0927:TSM $\mathrm{ECM}>2.0 . \mathrm{CO} ; 2$

Janjić Z.I., 2000, Comments on "Development and evaluation of a convection scheme for use in climate models", Journal of the Atmospheric Sciences, 57 (21), 3686-3686, DOI: 10.1175/1520-0469(2000)057<3686:CODAEO >2.0.CO;2 Jones C., Giorgi F., Asrar G., 2011, The Coordinated Regional Downscaling Experiment: CORDEX. An international downscaling link to CMIP5, CLIVAR Exchanges, 56 (16), 34-41, http://www.clivar.org/sites/default/files/documents/ Exchanges56.pdf

Kain J.S., 2004, The Kain-Fritsch convective parameterization: an update, Journal of Applied Meteorology, 43 (1), 170-181, DOI: 10.1175/1520-0450(2004)043<0170:TKCPAU>2.0.CO;2

Kain J.S., Baldwin M.E., Weiss S.J., 2003, Parameterization updraft mass flux as a predictor of convective intensity, Weather Forecasting, 18 (1), 106-116, DOI: 10.1175/1520-0434(2003)018<0106:PUMFAA >2.0.CO;2

Kain J.S., Fritsch J.M., 1990, A one-dimensional entraining/ detraining plume model and its application in convective parameterization, Journal of the Atmospheric Sciences, 47 (23), 2784-2802, DOI: 10.1175/1520-0469(1990)047<2784:AOD EPM>2.0.CO;2

Kain J.S., Fritsch J.M., 1993, Convective parameterization for mesoscale models: The Kain- Fritsch scheme, [in:] The representation of cumulus convection in numerical models, K.A. Emanuel, D.J. Raymond (eds.), American Meteorological Society, 165-170, DOI: 10.1007/978-1-935704-13-3_16

Klein C., Heinzeller D., Bliefernicht J., Kunstmann H., 2015, Variability of West African monsoon patterns generated by a WRF multi-physics ensemble, Climate Dynamics, 45 (9-10), 2733-2755, DOI: 10.1007/s00382-015-2505-5

Kothe S., Lüthi D., Ahrens B., 2014, Analysis of the West African Monsoon system in the regional climate model COSMO-CLM, International Journal of Climatology, 34 (2), 481-493, DOI: 10.1002/joc. 3702

Kreitzberg C.W., Perkey D.J., 1976, Release of potential instability: Part I, A sequential plume model within a hydrostatic primitive equation model, Journal of the Atmospheric Sciences, 33 (3), 456-475, DOI: 10.1175/1520-0469(1976)033<0456:ROPIPI $>2.0 . \mathrm{CO} ; 2$

Leroux S., Hall N.M.J., 2009, On the relationship between African easterly waves and the African easterly jet, Journal of the Atmospheric Sciences, 66 (8), 2303-2316, DOI: 10.1175/2009JAS2988.1 
Liebmann B., Smith, C.A., 1996, Description of a complete (interpolated) Outgoing Longwave Radiation Dataset, Bulletin of the American Meteorological Society, 77 (6), 1275-1277, https://www.jstor.org/stable/26233278

Liu P., Wang B., Sperber K.R., Li T., Meehl G.A., 2005, MJO in the NCAR CAM2 with the Tiedtke convective scheme, Journal of Climate, 18 (15), 3007-3020, DOI: 10.1175/JCLI3458.1

Ma L.-M., Tan Z.-M., 2009, Improving the behaviour of the cumulus parameterization for tropical cyclone prediction: Convection trigger, Atmospheric Research, 92 (2), 190-211, DOI: 10.1016/j.atmosres.2008.09.022

Mendes D., Marengo J.A., 2010, Temporal downscaling: a comparison between artificial neural network and autocorrelation techniques over the Amazon Basin in present and future climate change scenarios, Theoretical and Applied Climatology, 100 (3-4), 413-421, DOI: 10.1007/s00704-009-0193-y

Mitchell T.D., Jones P.D., 2005, An improved method of constructing a database of monthly climate observations and associated high-resolution grids, International Journal of Climatology, 25 (6), 693-712, DOI: 10.1002/joc.1181

Nikulin G., Jones C., Giorgi F., Asrar G., Büchner M., CerezoMota R., Christensen O.B., Déqué M., Fernandez J., Hänsler A., Meijgaard E.V., Samuelsson P., Sylla M.B., Sushama L., 2012, Precipitation climatology in an ensemble of CORDEXAfrica regional climate simulations, Journal of Climate, 25 (18), 6057-6078, DOI: 10.1175/JCLI-D-11-00375.1

Noble E., Druyan L.M., Fulakeza M., 2014, The sensitivity of WRF daily summer time simulations over West Africa to alternative parameterizations, Part I: African Wave Circulation, Monthly Weather Review, 142 (4), 1588-1608, DOI: 10.1175/ MWR-D-13-00194.1

Satyaban B., Ratnam J.V., Ratnam S.K., Behera C.J., de Rautenbach W., Ndarana T., Takahashi K., Yamagata T., 2014, Performance assessment of three convective parameterization schemes in WRF for downscaling summer rainfall over
South Africa, Climate Dynamics, 42 (11-12), 2931-2953, DOI: 10.1007/s00382-013-1918-2

Schumacher C., Houze Jr. R.A., 2003, Stratiform rain in the tropics as seen by the TRMM precipitation radar, Journal of Climate, 16 (11), 1739-1756, DOI: 10.1175/1520-0442(2003)016<1739: SRITTA $>2.0 . \mathrm{CO} ; 2$

Simpson J., Wiggert V., 1969, Models of precipitating cumulus towers, Monthly Weather Review, 97 (7), 471-489, DOI: 10.1175/1520-0493(1969)097<0471:MOPCT>2.3.CO;2

Steiner A.L., Pal J.S., Rauscher S.A., Bell J.L., Diffenbaugh N.S., Boone A., Sloan L.C., Giorgi F., 2009, Land surface coupling in regional climate simulations of the West African monsoon, Climate Dynamics, 33 (6), 869-892, DOI: 10.1007/s00382009-0543-6

Sylla M.B., Giorgi F., Ruti P.M., Calmanti S., Dell'Aquila A., 2011, The impact of deep convection on the West African summer monsoon climate: a regional climate model sensitivity study, Quarterly Journal of the Royal Meteorological Society, 137 (659), 1417-1430, DOI: 10.1002/qj.853

Tiedtke M., 1989, A comprehensive mass flux scheme for cumulus parameterization in large-scale models, Monthly Weather Review, 117 (8), 1779-1800, DOI: 10.1175/1520-0493(1989)117<1779:ACMFSF>2.0.CO;2

Yavinchan S., Exell R.H.B., Sukawat D., 2006, Precipitation forecasts by the new Kain-Fritsch convection scheme during the extreme precipitation event in Southern Thailand, [in:] The $2^{\text {nd }}$ Joint International Conference on "Sustainable Energy and Environment", 21-23 November 2006, Bangkok, Thailand, available at http://www.jgsee.kmutt.ac.th/see1/cd/file/D-006. pdf (data access 13.02.2019)

Yin X., Gruber A., Arkin P., 2004, Comparison of the GPCP and CMAP merged gauge-satellite monthly precipitation products for the period 1979-2001, Journal of Hydrometeorology, 5 (6), 1207-1222, DOI: 10.1175/JHM-392.1 